http://nv.nltu.edu.ua

https://doi.org/10.15421/40280528

Article received 10.05.2018 $p$.

Article accepted 41.05.2018 p.

\title{
КІЛЬКІСНИЙ АНАЛІЗ ОРІЄНТАЦІЇ ТА ВИДОВЖЕНОСТІ ЗЕРЕН НА МЕТАЛОГРАФІЧНИХ ЗОБРАЖЕННЯХ ЗА ДОПОМОГОЮ ПЕРЕТВОРЕНЬ ХАФА
}

\begin{abstract}
Однією з форм представлення результатів неруйнівного контролю різноманітних металоконструкцій $\epsilon$ металографічні зображення. Це зображення мікроструктури металу, які формуються за допомогою мікроскопа і фотофіксувального пристрою. 3 погляду матеріалознавства, мікроструктура відображає внутрішню будову металу та складається із різноманітних об'єктів - зерен, меж зерен, карбідів, різноманітних включень тощо, які характеризуються розміром, формою, орієнтацією. Мікроструктура матеріалу є віддзеркаленням його фізико-механічних характеристик. Отже, актуальною є задача аналізу мікроструктури матеріалів, яка надасть нові можливості щодо кількісного оцінювання їх фізико-механічних властивостей. Візуальний аналіз не забезпечує потрібної швидкодії та точності опрацювання, тому для вирішення задачі аналізу мікроструктури найдоцільніше використовувати методи оброблення цифрових зображень. Залежно від поставленої мети, задача аналізу мікроструктури полягатиме у пошуку та обчисленні метричних розмірів складників мікроструктури, оцінюванні їх форми, формуванні певної статистики тощо. У цій роботі розроблено метод кількісного аналізу орієнтації та видовженості зерен на металографічних зображеннях за допомогою перетворення Хафа. Результати цього аналізу є основою для досліджень залишкових напружень та пластичних деформацій металів.
\end{abstract}

Ключові слова: аналіз текстури; мікроструктура матеріалу; цифрові зображення; межі зерен; залишкові напруження; пластична деформація.

Вступ. Мікроструктуру будь-якого металевого сплаву можна представити як набір структурних елементів одного чи декількох типів. У площині зображення шліфа ці структури відображаються у вигляді деяких геометричних фігур, які характеризуються певною формою та геометричними параметрами.

Одним із параметрів, які характеризують структуру, $\epsilon$ усереднена орієнтація зерен чи ії відсутність. Якщо на поверхні шліфа відсутня будь-яка переважаюча спрямованість меж зерен, то таку структуру називають ізометричною. У випадку орієнтованих структур межі зерен металу є частково чи повністю зорієнтованими вздовж деякого напрямку. Кількісне оцінювання орієнтації зерен $\epsilon$ важливим у розв'язуванні багатьох матеріалознавчих задач (Iliushin, 1963). Зокрема, орієнтація зерен матеріалу здебільшого виникає внаслідок його пластичної деформації. Неоднорідність розподілу пластичної деформації $\epsilon$ причиною виникнення залишкових напружень. Одним із основних підходів до оцінювання залишкових напружень $є$ рентгенівський метод. Він дає змогу кількісно оцінювати залишкову напруженість через рівень спотворення кристалічної гратки. Недоліком такого підходу є те, що він вимагає дороговартісного рентгенівського обладнання, а спотворення кристалічної гратки аналізуються не в автоматизованому чи авто- матичному режимі, що може призвести до значних похибок через наявність людського фактору.

Тому актуальним є розроблення технології, яка давала б змогу автоматизувати аналіз орієнтації зерен матеріалу. Ускладнення сучасних задач аналізу цифрових зображень призвело до цього, що можливостей традиційних підходів до опрацювання візуальних даних $є$ недостатньо. Це зумовило необхідність розроблення нових та адаптації відомих технологій для вирішення поставлених задач. Доволі часто для аналізу об'єктів на цифрових зображеннях використовується перетворення Хафа (Atiquzzaman, 1992). Відомо, що цей підхід дає змогу локалізовувати на зображенні прямі, кола, еліпси.

Розглянемо найпростіший випадок пошуку прямих на зображенні. Пряма на площині описується рівнянням $y=k \cdot x+b$ та може бути задана двома точками. У перетворені Хафа пряма описується двома параметрами - $\rho$ та $\theta$. $\rho$ - це відстань від початку координат до прямої, а $\theta$ - кут між прямою, перпендикулярною до заданої та додатним напрямком осі абсцис (рис. 1).

Пряма у просторі Хафа представляється одним чітким піком з координатами $(\rho, \theta)$ (рис. $2, a)$. На багатьох реалістичних зображеннях, зокрема металографічних, $\epsilon$ лінії, які тільки з деяким наближенням можна назвати прямими. Їх представлення у просторі Хафа (рис. 2,б)

Інформація про авторів:

Журавель Ігор Михайлович, канд. техн. наук, ст. науковий співробітник, доцент кафедри безпеки інформаційних технологій. Email: izhuravel@ukr.net; https://orcid.org/0000-0003-1114-0124

Максимович Володимир Миколайович, д-р техн. наук, професор, завідувач кафедри безпеки інформаційних технологій. Email: volodymyr.maksymovych@gmail.com; https://orcid.org/0000-0001-8435-4129

Цитування за ДСтУ: Журавель І. М., Максимович В. М. Кількісний аналіз орієнтації та видовженості зерен на металографічних зображеннях за допомогою перетворень Хафа. Науковий вісник НЛтУ України. 2018, т. 28, № 5. С. 135-139.

Citation APA: Zhuravel, I. M., \& Maksymovych, V. M. (2018). Quantitative analysis of orientation and elongation of grains on metallographic images using hough transformations. Scientific Bulletin of UNFU, 28(5), 135-139. https://doi.org/10.15421/40280528 
буде відрізнятися від прямих ліній (див. рис. 2,a), а самі точки піків $(\rho, \theta)$ будуть більш розпливчастими.

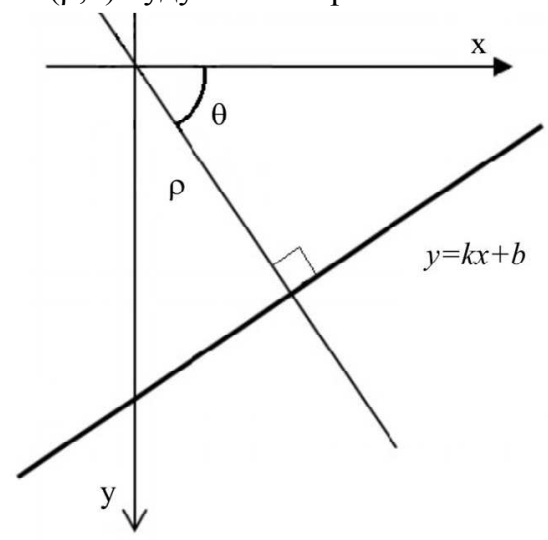

Рис. 1. Представлення прямої у просторі Хафа

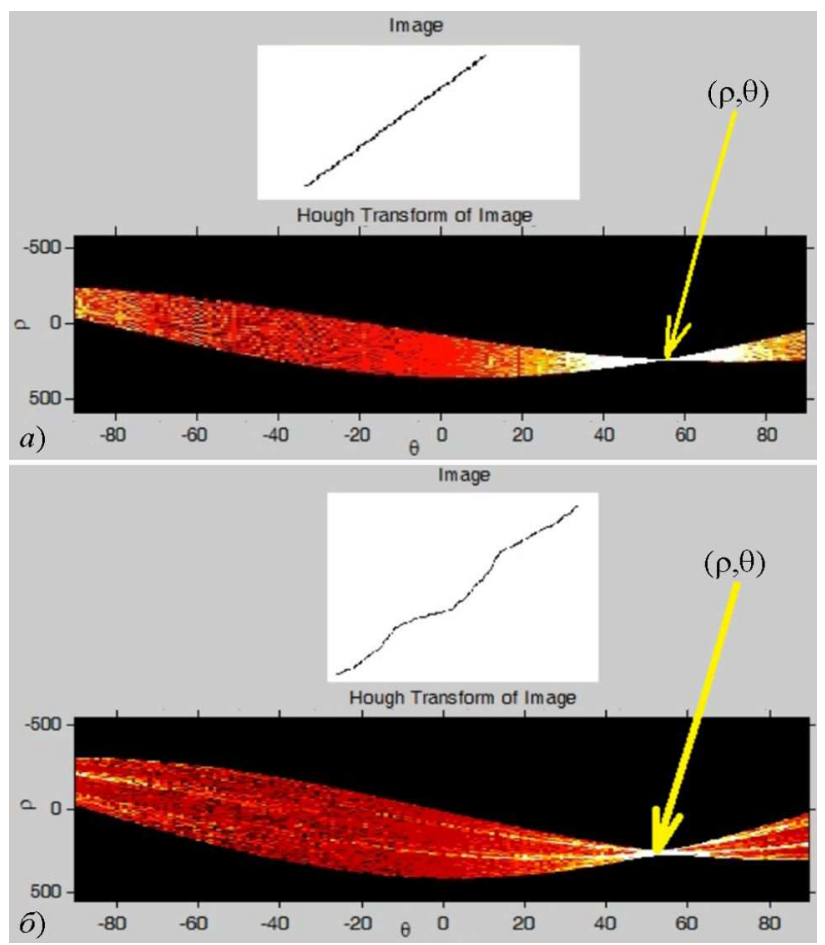

Рис. 2. Зображення прямої (а), умовно прямої лінії (б) та відповідне перетворення Хафа

Багато зображень мають складну структуру, тому виявити на них прямі чи умовно прямі лінії $\epsilon$ досить складно. Перетворення Хафа дає змогу виявляти ці об'єкти на складноструктурованих зображеннях. Застосуємо цю технологію для аналізу орієнтації зерен на металографічних зображеннях та кількісної оцінки їх видовження.

Я зазначено вище, оцінка орієнтації та видовження складників, зокрема зерен металів, є важливим параметром у дослідженні багатьох матеріалознавчих задач, зокрема деформацій, залишкових напружень, деградацій матеріалу. У багатьох роботах (Saltykov, 1976; Iliushin, 1963) для вивчення зміни орієнтування та видовження елементів мікроструктури проводили такі експерименти - зразки металу розтягували, стискали, крутили, а потім вивчали як змінилася їх мікроструктура до та після експерименту. Встановлено, що до прикладення зовнішніх дій зерна $\epsilon$ переважно округлої форми та не мають чітко вираженої орієнтації. Із збільшенням деформацій зерна витягуються вздовж певних ліній. Коли зовнішня дія $\epsilon$ істотною, то це призводить до текстурної деформації, а зерна металу зорієнтовуються вздовж сили навантаження та витягуються пропорційно до прикладеної сили. Зважаючи на зазначене вище, важливою є задача аналізу орієнтації зерен металу та кількісного оцінювання їх видовження.

Аналіз орієнтації зерен металу. Дослідимо розроблений метод 3 використанням перетворення Хафа для визначення напрямку орієнтації зерен металу. За вхідне використаємо змодельоване зображення меж зерен, яке представлене на рис. 3,a. Застосуємо до цього зображення перетворення Хафа (див. рис. 3, б).

До рис. 3 необхідно дати пояснення стосовно систем координат, які використовуються у формуванні вхідних зображень, кута повороту $\alpha$ та їх представлення у просторі Хафа. Для вхідного зображення використовується традиційна система координат - додатний напрямок кута повороту спрямований від осі $O X$ проти руху годинникової стрілки. Для зображення, яке представлене на рис. 3, $a$, кут повороту визначається напрямком видовженості зерен металу на зображенні, тобто їх орієнтацією. При представленні цього зображення в просторі Хафа (див. рис. 3,б) використовується система відліку, де додатний напрямок кута повороту спрямований від осі $O X$ за рухом годинникової стрілки, але під кутом повороту мається на увазі кут повороту не прямої, а перпендикуляру до неї. У просторі Хафа цей кут прийнято позначати буквою $\theta$.

На рис. 3,б, яке є представленням вхідного рис. 3, $a$ у просторі Хафа, білими квадратиками позначено максимальні значення акумулюючої матриці. Зазначимо, що ці піки групуються біля таких значень $\theta$ у просторі Хафа, які відповідають перпендикуляру до напрямку орієнтації зерен металу.

3 рис. 3,a видно, що більшість зерен є зорієнтовані у вертикальному напрямку, тобто $\alpha=90^{\circ} .3$ гістограми на рис. 3,6 видно, що максимальна кількість піків згрупована біля $\theta=0^{\circ}$, що відповідає перпендикуляру до вертикальної лінії ( $\alpha=90^{\circ}$ ). Отже, розроблений метод дає змогу в автоматичному режимі визначати переважаючий напрям орієнтації зерен металу на зображенні шліфа.

Визначення видовженості зерен металу. Представлене на рис. 3,a тестове зображення має доволі чітку видовженість зерен. Зерна металів на реальних металографічних зображеннях характеризуються різним рівнем видовженості або тії відсутністю. У роботі розроблено метод кількісного оцінювання рівня видовженості зерен металу.

Для проведення дослідження змоделюємо зображення $з$ різним рівнем видовження зерен металу (рис. $4, a, 2$ ). Оскільки зображення можуть бути сформовані під різним кутом повороту в площині предметного стола, то параметр, який характеризує рівень видовження, повинен бути однаковим для різних кутів повороту та не залежати від нього, тобто бути інваріантним. Застосуємо до кожного із зображень цього набору перетворення Хафа (Atiquzzaman, 1992; Saltykov, 1976) (див. рис. $4, \sigma, \partial$ ). Із зображень (див. рис. 4,б,d) видно, що подібно до попередніх дослідів (див. рис. 3), локальні максимуми розподілені по полю зображення не рівномірно, а групуються біля певних значень кута $\theta$ у просторі Хафа. Для детальнішого налізу побудуємо для кожного вхідного зображення гістограму розподілу локальних максимумів у просторі Хафа залежно від кута $\theta$ (див. рис. $4,8, e)$. 


\begin{tabular}{|c|c|c|}
\hline $\begin{array}{c}\text { Зображення, сформоване } \\
\text { під кутом } \alpha\end{array}$ & $\begin{array}{c}\text { Представлення зображення } \\
\text { у просторі Хафа }\end{array}$ & $\begin{array}{c}\text { Гістограма розподілу прямих } \\
\text { під певним кутом }\end{array}$ \\
\hline
\end{tabular}
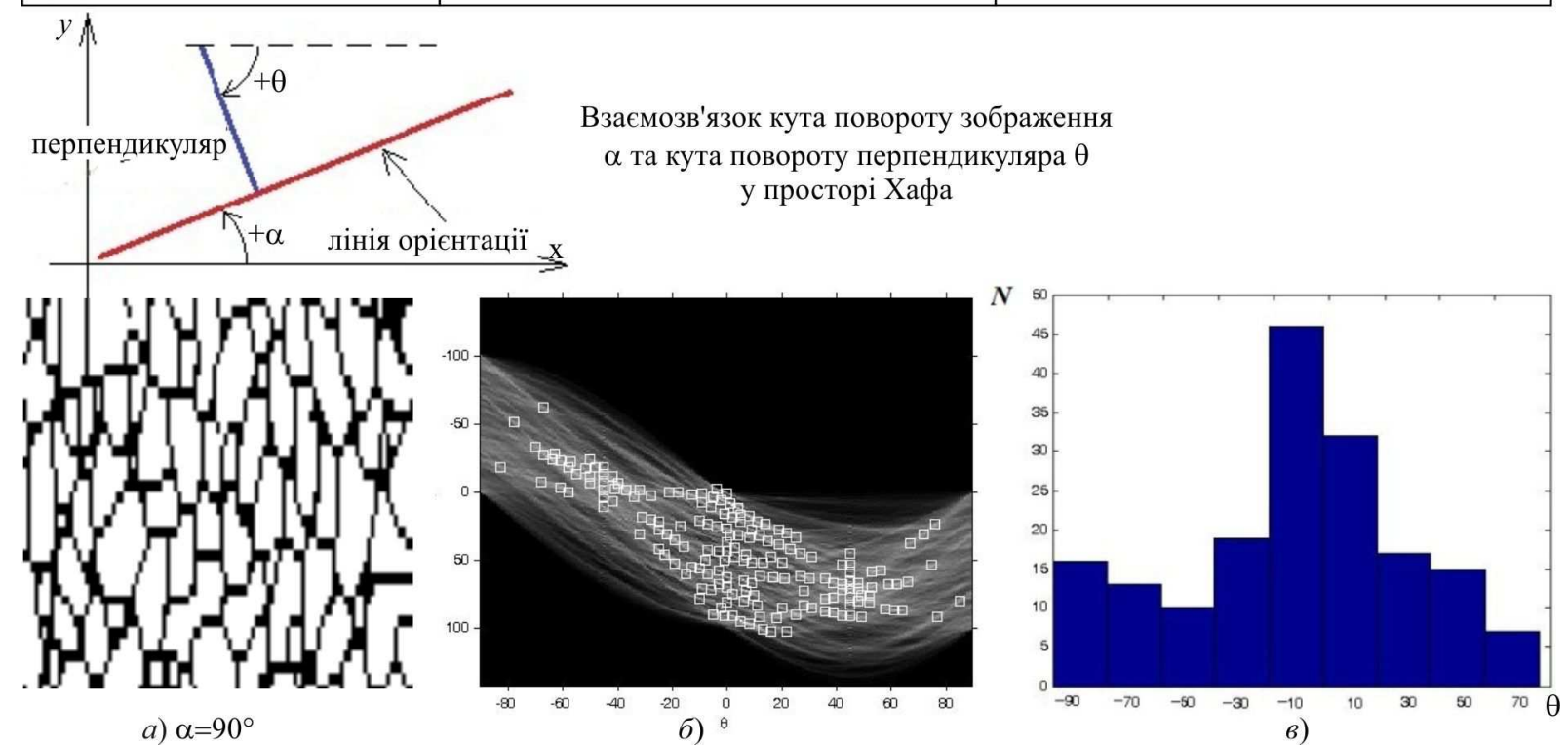

Рис. 3. Дослідження методу визначення напрямку орієнтації зерен металу з використанням перетворення Хафа

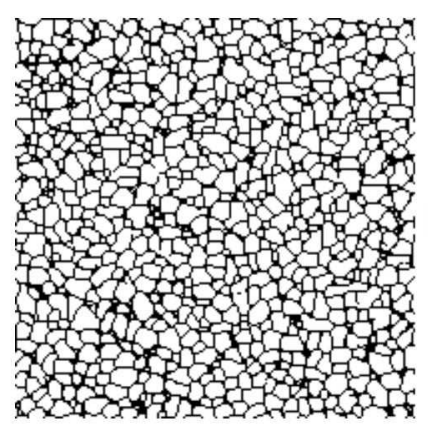

a) $\alpha=0^{\circ}$

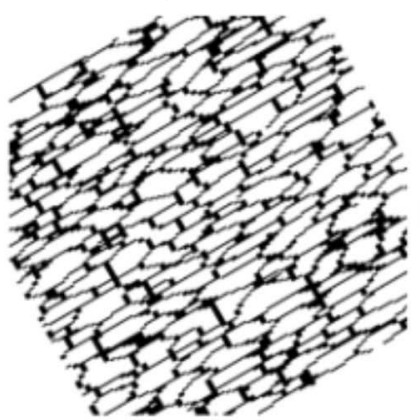

2) $\alpha=30^{\circ}$

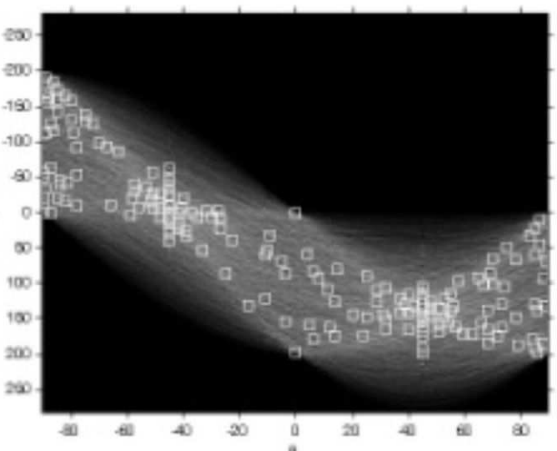

б)

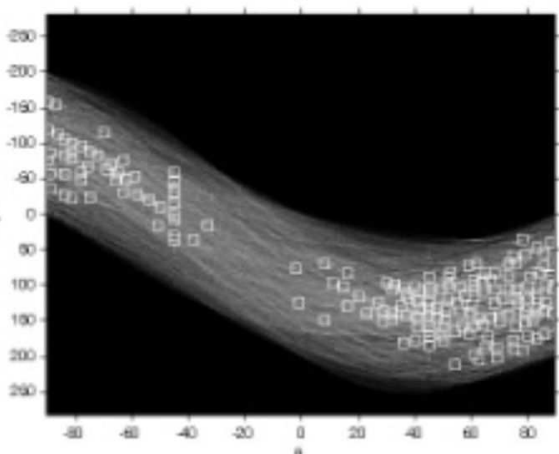

$\partial)$

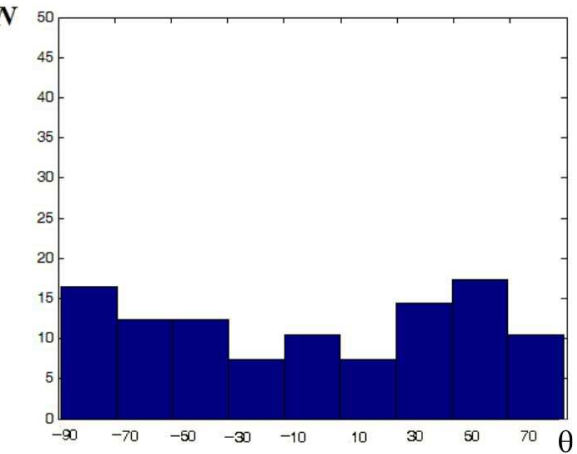

в)

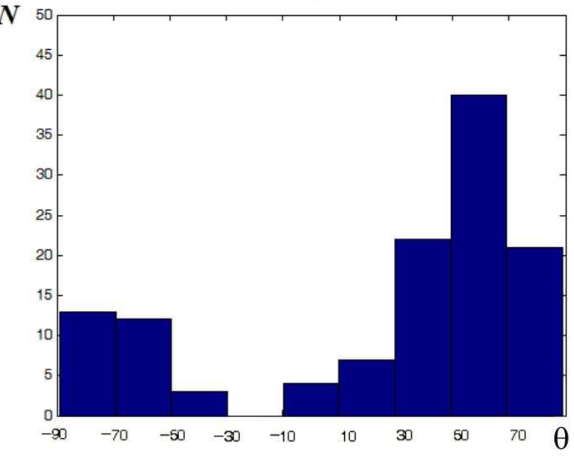

e) $\theta=60^{\circ}$

Рис. 4. Дослідження методу кількісного оцінювання рівня видовженості зерен металу

Проведемо аналіз сформованих гістограм (див. рис. $4,6, e)$. Кожна із цих гістограм має максимум, який для вхідних зображень (рис. 4,a,z) є різним та відповідає різним кутам $\theta$. Більшій видовженості зерен металу відповідає більше абсолютне значення максимуму. Для прикладу, на рис. $4, a$ зерна металу не мають очевидного видовження в деякому напрямку, тому і відповідна їм гістограма не має чітко виражених максимумів (див. рис. 4,8$)$. На рис. 4 , г зерна металу $є$ істотно видовженими. Видовженість зерен орієнтована в напрямку прямої, яка розміщена під кутом $\alpha=30^{\circ}$ до осі $O X$. Перпендикуляр до цієї прямої розміщений під кутом $\theta=60^{\circ}$ та відповідає координаті максимуму в просторі Хафа (рис. $4, e)$ для цього зображення.
Другим важливим аспектом в аналізі гістограм, представлених на рис. 4, 6 та $e, \epsilon$ те, що моди цих гістограм пропорційні до видовження зерен металу на відповідних зображеннях рис. 4, $a$ та г. Отже, на основі пронормованого значення цих максимумів можна кількісно оцінювати рівень видовженості $S$ зерен, який своєю чергою корелює з іншими фізико-механічними характеристиками, зокрема такими, як пластична деформація, міцність, пружність, твердість тощо.

Застосуємо розроблений у роботі метод кількісного оцінювання видовження зерен металу на основі перетворень Хафа для дослідження металографічних зображень шліфів сталі $12 Х 1 М Ф$, вирізаних з прямолінійної ділянки та зони гину труби парогону ТЕС після 
133431 год експлуатації (Zhuravel', et al., 2009). Результати проведених досліджень представлено у таблиці.

Таблиця. Результати кількісного оцінювання видовження зерен шліфів сталі 12Х1МФ, вирізаних 3 прямолінійної ділянки та зони гину труби парогону ТЕС

\begin{tabular}{|c|c|c|c|c|c|c|c|c|c|}
\hline \multicolumn{7}{|c|}{ Зображення шліфа з прямої ділянки труби } \\
(Zhuravel', et al., 2009) \\
\hline $\begin{array}{c}\text { Відстань від } \\
\text { внутрішньої } \\
\text { стінки, мм }\end{array}$ & 2,5 & 5 & 9 & 12 & 17 & 20 & 27 & 32 & 33 \\
\hline $\begin{array}{c}\text { Витягнутість } \\
\text { зерен, } S\end{array}$ & 18 & 18 & 17,9 & 17,6 & 16,9 & 17,4 & 18,6 & 15,5 & 16,9 \\
\hline Зображення шліфа із зони гину труби (Zhuravel', et al., 2009) \\
\hline $\begin{array}{c}\text { Відстань від } \\
\text { внутрішньої } \\
\text { стінки, мм }\end{array}$ & 2,5 & 10 & 14 & 19 & 23 & 27 & 29 \\
\hline $\begin{array}{c}\text { Витягнутість } \\
\text { зерен, } S\end{array}$ & 21,6 & 22,5 & 26,1 & 27,6 & 25,5 & 27,1 & 23,5 \\
\hline
\end{tabular}

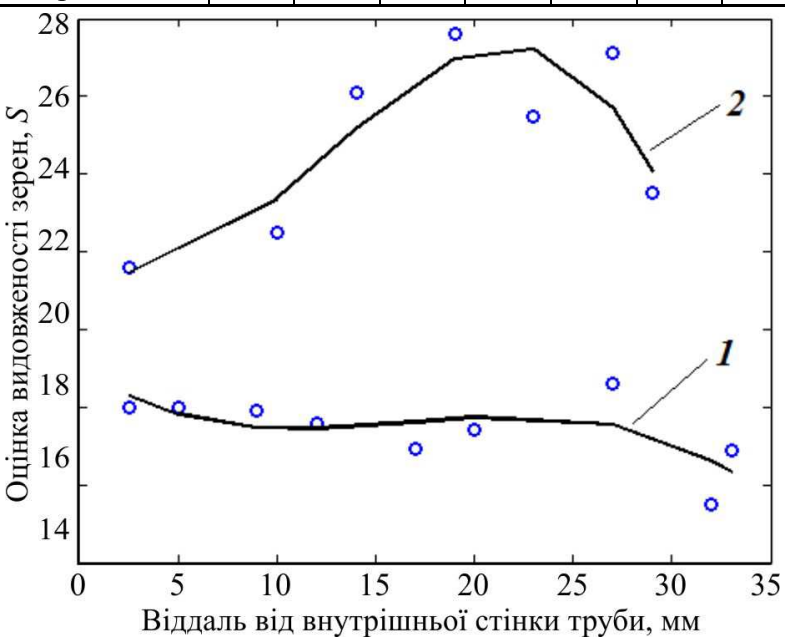

Рис. 5. Оцінка видовженості зерен шліфів сталі 12 Х1МФ, вирізаних з прямолінійної ділянки (1) та зони гину (2) труби парогону ТЕC
Параметр видовженості $S$ обчислюється як відношення максимальної кількості піків при певному куті $\theta$ до загальної їх кількості у просторі Хафа (див. рис. $4,8, e)$.

Для більш наочного відображення результатів (див. рис. 5) проведеного дослідження представимо їх у вигляді графіка (рис. 5). Представлені на рис. 6 результати добре корелюють $з$ результатами розподілу розміру зерен та зміни твердості залежно від віддалі від внутрішньої стінки труби, які отримані у (Zhuravel', et al., 2009). Це дає змогу виявити взаємозв'язок між видовженістю $S$ зерен металу, їх усередненим діаметром та фізико-механічними характеристиками металу, які отримані у роботі (Zhuravel', et al., 2009).

На прямолінійній ділянці труби парогону видовженість зерен істотно менша за видовженість зерен у зоні гину. Це свідчить про те, що деформаційна текстура в зоні гину є вираженішою. Видовженість та орієнтація зерен тісно пов'язана 3 пластичним деформаціями. Орієнтація видовженості зерен збігається із напрямком прикладених напружень. Цим можна пояснити збільшення оцінки видовженості зі зростанням відстані від внутрішньої стінки труби в зоні гину.

\section{Перелік використаних джерел}

Atiquzzaman, M. (1992). Multirezolution Hough transform - inefficient method of detecting patterns in images. IEEE Trans. on Pattern Analysis and Machine Intelligence, 14(11), 1090-1095.

Iliushin, A. A. (1963). Plastichnost. Osnovy obshhei matematicheskoi teorii. Moscow: AN SSSR. 272 p. [In Russian].

Saltykov, S. A. (1976). Stereometricheskaia metallografiia. Moscow: Metalurgiia. [In Russian].

Zhuravel', I. M., Svirs'ka, L. M., Student, O. Z., Vorobel', R. A., \& Nykyforchyn, H. M. (2009). Automated determination of grain geometry in an exploited steam-pipeline steel. Materials Science, $45(3), 350-357$.

И. М. Журавель, В. Н. Максимович

Национальный университет "Львовская политехника", г. Львов, Украина

\section{КОЛИЧЕСТВЕННЫЙ АНАЛИЗ ОРИЕНТАЦИИ И УДЛИНЕННОСТИ ЗЕРЕН НА МЕТАЛЛОГРАФИЧЕСКИХ ИЗОБРАЖЕНИЯХ С ПОМОЩЬЮ ПРЕОБРАЗОВАНИЙ ХАФА}

Одной из форм отображения результатов неразрушающего контроля различных металлоконструкций являются металлографические изображения. Это изображения микроструктуры металла, которые формируются с помощью микроскопа и фотофиксирующего устройства. С точки зрения материаловедения, микроструктура представляет внутреннее строение металла и состоит из различных объектов - зерен, границ зерен, карбидов, различных включений и т. п., которые характеризуются размером, формой, ориентацией. Микроструктура материала является отражением его физико-механических характеристик. Таким образом, актуальной является задача анализа микроструктуры материалов, которая предоставит новые возможности для количественной оценки их физико-механических свойств. Визуальный анализ не обеспечивает нужной производительности и точности обработки, поэтому для решения задачи анализа микроструктуры наиболее целесообразно использовать методы обработки цифровых изображений. В зависимости от поставленной цели, задача анализа микроструктуры заключаться в поиске и вычислении метрических размеров составляющих микроструктуры, оценке их формы, формировании определенной статистики и тому подобное. В данной работе разработан метод количественного анализа ориентации и удлинения зерен на металлографических изображениях с помощью преобразования Хафа. Результаты этого анализа являются основой для исследований остаточных напряжений и пластических деформаций металлов.

Ключевые слова: анализ текстуры; микроструктура материала; цифровые изображения границ зерен; остаточные напряжения; пластическая деформация.

I. M. Zhuravel, V. M. Maksymovych Lviv Polytechnic National University, Lviv, Ukraine

\section{QUANTITATIVE ANALYSIS OF ORIENTATION AND ELONGATION OF GRAINS ON METALLOGRAPHIC IMAGES USING HOUGH TRANSFORMATIONS}

One of the forms of presentation of the results of non-destructive control of various metal structures is the metallographic images. This is a mapping of the metal microstructure that is formed by a microscope and a photoconductive device. In terms of materials science, the microstructure reflects the internal structure of the metal and consists of a variety of objects - grains, grain boundaries, carbides, various inclusions, etc., which are characterized by size, shape, orientation. The microstructure of the material is a 
reflection of its physical and mechanical characteristics. Thus, the problem of microstructure analysis of materials is urgent, which will provide new possibilities for quantifying their physical and mechanical properties. Visual analysis does not provide the required speed and accuracy of processing, therefore, to solve the problem of microstructure analysis, the most expedient to use the methods of processing digital images. Depending on the objective, the task of microstructure analysis will consist in finding and calculating the metric sizes of the components of the microstructure, evaluating their shape, forming a certain statistic, etc. In this paper, the method of quantitative analysis of the orientation and elongation of grains on metallographic images using the Hough transform has been developed. The results of this analysis are the basis for research of residual stresses and plastic deformations of metals.

Keywords: texture analysis; microstructure of the material; digital images; grain boundaries; residual stresses; plastic deformation. 